\title{
Covariates of prehypertension in Oman
}

\author{
Sanam Anwar 1,*, Bushra Aleem², Ghadeer Jamal Moslhey ${ }^{3}$, Hajir Hamed Rashid ${ }^{4}$ \\ ${ }^{1} \mathrm{HOD},{ }^{2-4}$ Resident, Dept. Epidemiology \& Public Health, College of Medicine \& Health Sciences, National University of Science and \\ Technology, Oman
}

\section{*Corresponding Author: Sanam Anwar}

Email: sanam@omc.edu.om

\begin{abstract}
Introduction: The WHO report in 2010 on country profiles estimated that non-communicable diseases account for nearly $83 \%$ of the total deaths in Oman. Prehypertension can predict cardiovascular morbidities.

Objectives: The study was carried out with the objective of identifying important covariates of prehypertension in Oman.

Materials and Methods: In the cross sectional study, a structured questionnaire was used for data collection which had details on sociodemography along with measurements of blood pressure and anthropometry. Binary logistic regression was used to identify important predictors of prehypertension. Wald's test was used to see the significance of coefficients of regression.

Results: 233 individuals (46.6\%) suffered from prehypertension out of the total 500 study population. Mean age of prehypertensives was $42.48 \pm 1.2$. Most of them (70.8\%) were males and $29.2 \%$ were females. $49.9 \%$ had secondary education and $46.4 \%$ had higher secondary education. Wald test was significant for gender $($ Wald $=7.263, \mathrm{p}=0.007)$; sedentary occupation $($ Wald $=4.518, \mathrm{p}=0.034)$ and age $(\mathrm{Wald}=$ $10.870, \mathrm{p}=0.001)$. Percentage accuracy of classification of the model was $78.8 \%$. The predictor model $($ chisquare $=29.6$, $\mathrm{p}=0.000)$ accounted for $14.7 \%$ variability in prehypertension. Area under the curve was $0.725, \mathrm{p}=0.000$.
\end{abstract}

Conclusion: Age, occupation and gender were seen as important predictors of prehypertension in the study population.

Keywords: Prehypertension, covariates, Age, Education, BMI.

\section{Introduction}

Hypertension is a known predictor of cardiovascular disease, cerebrovascular accidents, and death with regionally variable and increasing magnitude. ${ }^{1}$ Worldwide the prevalence of hypertension varies from $5.2 \%$ to $70.7 \%$ in the adults, and it is estimated that more than 1.5 billion individuals have hypertension currently. ${ }^{2}$ The WHO report in 2010 on country profiles estimated that noncommunicable diseases account for nearly $83 \%$ of the total deaths in Oman. ${ }^{3}$

The concept of prehypertension has been defined to draw attention to the increased risks resulting from increased blood pressure. In 2003, the seventh Report of JNC-7 proposed prehypertension as a category between normal blood pressure and hypertension. ${ }^{4}$ They defined prehypertension as systolic blood pressure of 120-139 $\mathrm{mmHg}$ and/or diastolic blood pressure of $80-89 \mathrm{mmHg}$ in adults. According to JNC-7, prehypertensive individuals have a greater risk of getting hypertension than those with normal blood pressure levels. ${ }^{5}$ Prehypertension was known by different names in the past, some called it transient hypertension or borderline hypertension and others just named it as high-normal BP. Today the terminology has changed, but prehypertension is considered as a precursor of hypertension and is known to be associated with morbidity and mortality from cardiovascular disease. Moreover, prehypertension is often closely linked to target organ damage, such as early arteriosclerosis, small vascular damage, coronary artery calcification, vascular remodeling, and left ventricular hypertrophy. ${ }^{6,7}$

The Framingham Heart Study reported that within 4 years, $50 \%$ of patients 65 years of age with blood pressure of 130 to 139 systolic and 85 to $89 \mathrm{~mm} \mathrm{Hg}$ diastolic progressed to hypertension. ${ }^{5}$ Player et al reported in his study that the patients who had prehypertension, $26 \%$ developed hypertension within 4 years. $^{8}$ Fareed et al reported that prehypertension was associated with a 1.7 times higher likelihood of coronary artery disease and a 3.5fold increase in myocardial infarction. ${ }^{9}$

The Oman health survey 2008 found that $19.6 \%$ males and $15.2 \%$ females had prehypertension. ${ }^{3}$ Few studies from urban India reported $32 \%$ prevalence of prehypertension. ${ }^{10,11}$ The pooled prevalence of prehypertension from meta-analysis of worldwide studies was reported as $38 \% .{ }^{12}$ Prehypertension with the presence of obesity may further increase the correlation of developing hypertension. Several studies have reported the association of higher waist circumference with a greater prevalence of prehypertension and hypertension. ${ }^{13}$ Not many studies have been conducted in Oman in the field of prehypertension. In prediabetic adults in Oman the prevalence of pre hypertension was reported as $54.1 \%$ in Omani adults. ${ }^{14}$ Another study in Oman observed $45 \%$ prevalence of prehypertension in population sampled from national screening program of chronic non communicable diseases in primary health care institutions. ${ }^{15}$ Thus the present study was carried out with the objective of identifying important covariates of prehypertension in Oman.

\section{Materials and Methods}

A Cross sectional study was done in South Batinah governorate in Oman for a period of 6 months in 2014. The participants were visitors seated in the visiting area who accompanied the patients coming to the Rustaq polyclinic. The inclusion criteria was adults more than 18 years of age and those who gave informed consent to participate in the study. Visitors who either did not give consent to participate in the study or were less than 18 years age were excluded 
from the study. The estimated sample size was 469, considering the prevalence of prehypertension in Omani adults as $45 \%$, with $10 \%$ variability in the estimated prevalence. Simple random sampling was used to identify the participants. A total of 500 people who gave consent participated in the study. Written informed consent was taken from all the participants. Research approval was given by the Ministry of Health. A prevaildated structured questionnaire was used to collect information on socio demography along with anthropometric and blood pressure measurements. Blood pressure was measured with sphygmomanometer. The average of two readings was used to define prehypertension. ${ }^{4}$ WHO guidelines were used to measure weight and height. ${ }^{16}$ Body mass index was calculated by dividing the weight (in $\mathrm{kg}$ ) by height in meter squared. BMI classification based on WHO as $<18.5$ (underweight), 18.5 to 24.9 (normal), and $\geq 25$ (overweight) was used. ${ }^{17}$ Waist circumference was measured to the nearest $0.5 \mathrm{~cm}$ by non-elastic measuring tape at the midpoint between the lower margin of the last rib and the top of the hip bone. Waist circumference in $\mathrm{cm}$ was divided by height in $\mathrm{cm}$ to get the waist height ratio. ${ }^{18}$ Cut off of 0.50 was taken for both males and females. ${ }^{19}$

Data was entered and analyzed in SPSS. Difference in frequencies was tested by chi square test and means were compared by unpaired t test. Multiple logistic regression stepwise method was fitted to identify important predictors of prehypertension versus normal blood pressure status with the adjusted odds ratio and $95 \%$ confidence intervals. A p value of less than 0.05 was considered statistically significant. Wald's was used to test the significance of regression coefficients. Model was tested for fitness of data by Hosmer Lemeshow test, area under ROC curve and Nagelkerke $\mathrm{R}$ square and percentage accuracy of classification.

\section{Results}

Out of the total 500 participants, $233 \quad(46.6 \%)$ individuals had prehypertension;203 (40.6\%) had hypertension and $64(12.8 \%)$ were normotensive. Prehypertensive population was made up of 165 males $(70.8 \%)$ and 68 females $(29.2 \%)$. Mean age of prehypertensives was $42.48 \pm 1.2$ which was significantly higher than the age of normotensives $(33.33 \pm 1.5), \mathrm{p}=0.001$. A higher percentage of prehypertensive population had secondary education $(49.9 \%)$ and $46.4 \%$ had higher secondary education (Table 1). Most of them had sedentary type occupation (47.7\%), compared to normotensive who were mostly with occupation involving physical activity, $\mathrm{p}=0.026$. People working in offices with straight duties from morning to evening were considered as involved in sedentary type of occupation; while the ones working in mines, ports or industries where active labour is involved were registered as occupation with physical activity. $46.7 \%$ did not do regular physical activity which was defined as exercise at home or gym or walking at least 5 days in a week. Moreover $41.7 \%$ of prehypertensives were also overweight. Mean BMI of normotensive $(25.1 \pm 0.7)$ was less than the prehypertensive population $(26.13 \pm 0.3)$. Similarly mean waist height ratio of normotensives $(0.52 \pm 0.01)$ was also less than prehypertensive population $(0.53 \pm 0.01)$ and the result was statistically significantly, $\mathrm{p}<0.05$.

Binary logistic regression was carried out to test the effects of age, gender, education, occupation, physical activity, body mass index and waist height ratio on the likelihood of participants having prehypertension (Table 2). The univariate regression analysis showed that as age increased by 1 year, likelihood of prehypertension increased significantly by $1.039, \mathrm{p}=0.000$. Males had 1.7 times, and those not doing regular physical activity had 1.5 times increased likelihood of developing prehypertension but the result was not statistically significant. People who attained only primary education had 2.6 times increased likelihood of developing prehypertension $(\mathrm{p}=0.006)$ compared to the participants with higher education. People with sedentary occupation had 1.9 times more likelihood of developing prehypertension $(\mathrm{p}=0.027)$. Participants with higher waist height ratio had 2 times more likelihood of developing prehypertension $(\mathrm{p}=0.018)$.

To develop a model for predicting prehypertension, multivariate binary logistic regression was performed by stepwise method. The model showed that age, occupation and gender were significant predictors of prehypertension, chisquare $=29.6, p=0.000$. Wald test was significant for gender $($ Wald $=7.263, \mathrm{p}=0.007)$; sedentary occupation (Wald $=4.518, \mathrm{p}=0.034)$ and age $(\mathrm{Wald}=10.870, \mathrm{p}=0.001)$. Percentage accuracy of classification of the model was $78.8 \%$. Nagelkerke $\mathrm{R}^{2}$ indicated that model accounted for $14.7 \%$ variability in prehypertension. Area under the curve was $0.725, p=0.000$ and insignificant Hosmer-Lemeshow ( $p>0.05)$ suggested that the model well fitted the data. Multivariate analysis showed that age, occupation and gender were important predictors of prehypertension in the study population (Table 3 ).

Table 1: Risk factors of prehypertension

\begin{tabular}{|lcccc|}
\hline Variable & Total (\%) & Normotensive (\%) & Prehypertensive (\%) & p value \\
\hline Gender & & & & \\
Female & 147 & $26(17.7)$ & $68(46.3)$ & 0.081 \\
Male & 353 & $38(10.8))$ & $165(46.7)$ & \\
Education & & & & 0.016 \\
Higher secondary & 179 & $32(17.9)$ & $83(46.4)$ & \\
Secondary & 109 & $18(16.5)$ & $96(49.5)$ & \\
Primary & 212 & $14(6.6)$ & $96(45.3)$ & \\
Occupation & & & &
\end{tabular}




\begin{tabular}{lllll|}
$\begin{array}{l}\text { Physical activity } \\
\text { Sedentary }\end{array}$ & 263 & $43(16.3)$ & $120(45.6)$ & 0.026 \\
$\begin{array}{l}\text { Regular exercise } \\
\text { Yes }\end{array}$ & 237 & $21(8.9)$ & $113(47.7)$ & \\
No & 134 & $23(17.2)$ & $62(46.3)$ & 0.144 \\
Waist height ratio & 366 & $41(11.2)$ & $171(46.7)$ & \\
$<$ cutoff & 136 & $30(22.1)$ & $72(52.9)$ & 0.017 \\
$\geq$ cutoff & 364 & $34(9.3)$ & $161(44.2)$ & 0.001 \\
$\begin{array}{l}\text { Age (Mean } \pm \text { SE) } \\
\text { BMI (Mean } \pm \text { SE) }\end{array}$ & $44.17 \pm 0.83$ & $33.33 \pm 1.51$ & $42.48 \pm 1.2$ & 0.258 \\
& $27.10 \pm 0.25$ & $25.09 \pm 0.73$ & $26.13 \pm 0.30$ & \\
\hline
\end{tabular}

Table 2: Covariates of prehypertension: univariatelogistic regression

\begin{tabular}{|l|c|c|c|c|}
\hline Variable & Beta coefficient & p value & Odds ratio & 95\% CI \\
\hline Age (years) & 0.038 & 0.000 & 1.039 & $1.017-1.061$ \\
\hline Gender & & & & \\
\hline Female & Reference & - & 1 & - \\
\hline Male & 0.507 & 0.083 & 1.660 & $0.936-2.945$ \\
\hline Education group & & & & \\
\hline Higher secondary & Reference & - & 1 & - \\
\hline Secondary & 0.146 & 0.671 & 1.157 & $0.591-2.264$ \\
\hline Primary \& Illiterate & 0.972 & 0.006 & 2.644 & $1.322-5.289$ \\
\hline Occupation & & & & \\
\hline Physical activity & Reference & - & 1 & \\
\hline Sedentary & 0.657 & 0.027 & 1.928 & $1.078-3.449$ \\
\hline Regular exercise & & & & \\
\hline Yes & Reference & - & 1 & \\
\hline No & 0.436 & 0.145 & 1.547 & $0.860-2.784$ \\
\hline Body mass index & & & & \\
\hline Underweight & Reference & - & 1 & - \\
\hline Normal weight & 0.902 & 0.096 & 2.464 & $0.851-7.134$ \\
\hline Overweight & 1.083 & 0.041 & 2.953 & $1.044-8.354$ \\
\hline Waist height ratio & & & & \\
\hline$<$ cutoff & Reference & - & 1 & - \\
\hline$\geq$ cutoff & -0.680 & 0.018 & 1.973 & $1.122-3.468$ \\
\hline
\end{tabular}

Table 3: Covariates of prehypertension: multiple logistic regression

\begin{tabular}{|l|c|c|c|c|}
\hline Variable & Beta coefficient & p value & Odds ratio & 95\% CI \\
\hline Age (years) & 0.037 & 0.001 & 1.038 & $1.015-1.061$ \\
\hline Gender & & & & \\
\hline Female & Reference & - & 1 & - \\
\hline Male & 0.868 & 0.007 & 2.382 & $1.267-4.478$ \\
\hline Occupation & & & & \\
\hline Physical activity & Reference & - & 1 & - \\
\hline Sedentary & 0.680 & 0.034 & 1.974 & $1.054-3.696$ \\
\hline
\end{tabular}

\section{Discussion}

The present study showed that prehypertension affects $46.6 \%$ of the Omani population, affecting more males than females. A similar prevalence of $45 \%$ prehypertension was reported by another study in Oman. ${ }^{15}$ While a higher prevalence of pre hypertension of $54.1 \%$ was reported by Ganguly et $\mathrm{al}^{14}$ in prediabetic Omani adults. Similar findings were reported in other studies; in Malaysia, it was reported $40.2 \%{ }^{20}$ and in another study $47.4 \% .^{21}$ While some published studies had lower figures; $36.1 \%$ in Brazilian adults $^{22}$ and $33.7 \%$ among adults in southern
Iran. ${ }^{23}$ Ferguson et $\mathrm{al}^{24}$ reported prevalence of $30 \%$ prehypertension in Jamaica and found the prevalence higher in males than in females. Studies from northern India ${ }^{10}$ and southern India $^{25}$ also found a higher prevalence of prehypertension in males and increasing age. Shahi et $\mathrm{al}^{20}$ reported $46.9 \%$ prevalence in females which was similar to this study $(46.3 \%)$. Ali et $\mathrm{al}^{15}$ in Oman also reported more males $(46 \%)$ than females (44\%) with prehypertension. Previous studies have observed higher levels of hypertension in postmenopausal than in premenopausal women. ${ }^{26,27}$ Therefore, frequent monitoring is needed for 
early detection of hypertension during the menopausal transition. Most of the prehypertensive population are left unrecognized which adds to the hidden burden of the problem. ${ }^{28}$ This phenomenon would further deteriorate the existing burden of non-communicable diseases worldwide. ${ }^{29}$

In the present study prehypertension was more (47.7\%) in people with sedentary type of occupation involving less physical activity and mean BMI of prehypertensives was also higher than normotensives $(26.13 \pm 0.3)$. A national survey in United States observed that $60 \%$ of American adults had either hypertension or prehypertension; and they also reported that older people, overweight population were affected disproportionately. ${ }^{30}$ Their findings were in agreement with the present study. Some other studies in Turkey and China also observed that obesity and weight gain is an important determinant of hypertension. ${ }^{31-34}$ Some studies showed that central obesity was significantly associated with prehypertension ${ }^{35,36}$ which is similar to the present study findings where significant number of prehypertensives $(44.2 \%)$ had more than the normal waist height ratio.

Age $(\mathrm{OR}=1.1)$, male gender $(\mathrm{OR}=2.3)$ and sedentary occupation $(\mathrm{OR}=1.9)$ were found to be important determinants of prehypertension in the present study. This was similar with the findings of Mona Soliman et $\mathrm{al}^{21}$ and Samuel et al. ${ }^{37}$ Ganguly et $\mathrm{al}^{14}$ in Oman also found that males were at a higher risk of developing prehypertension $(\mathrm{OR}=2.3)$; those with higher BMI had a twofold more risk. Ali et $\mathrm{al}^{15}$ also found age as an important correlate of prehypertension with a similar odds ratio as the present study. The cross-sectional study design and the conduct of the study in one area was one of the limitations of this study. Thus it did not represent the overall picture of adults throughout Oman. Keeping this in mid the causal relationship between risk factors and the development of prehypertension is limited.

\section{Conclusion}

Prehypertension was present in $46.6 \%$ individuals. The univariate regression analysis showed that the likelihood of prehypertension increased significantly with increasing age, in males, those not doing regular physical activity, people who attained only primary education, those with sedentary occupation and with higher waist height ratio. However on multivariate analysis age, sedentary occupation and male gender turned out to be important determinants of prehypertension in this study.

This study emphasizes the importance of detecting prehypertension in the early phase of life to combat its associated cardiovascular morbidities.

\section{Recommendations}

Awareness programs need to be tailor made for prehypertensive population based on life style modification related preventive strategies. Role of increased physical activity and weight reduction is of utmost importance as it is the biggest modifiable risk factor for prehypertension. More so if the young adults are screened early and targeted with good health education initiatives, the onset and progress of prehypertension can be halted with increasing age thus trying to combat the much higher burden of hypertension in Oman.

\section{Acknowledgements}

The authors duly acknowledge the financial support given by the Research Council as FURAP grant. The authors also acknowledge the cooperation of the Rustaq polyclinic staff.

\section{Conflict of Interest: Nil.}

\section{References}

1. Stephen PG, Jan NB, Daniel TL. Does prehypertension represent an increased risk for incident hypertensionand adverse cardiovascular outcome? Hypertens. 2009;54:954-955.

2. Danaei G, Finucane MM, Lin JK, Singh GM, Paciorek CJ, Cowan MJ, Farzadfar F, Stevens GA et al. National, regional, and global trends in systolic blood pressure since 1980:Systematic analysis of health examination surveys and epidemiological studies with 786 country-years and 5.4 million participants. Lancet. 2011;377:568-577.

3. Asya Al Riyami, Mahmoud Attia Abd Elaty, Magdi Morsi, Hilal Al Kharusi, Waleed Al Shukaily, Sanjay Jaju: Oman World Health Survey: Part 1 - Methodology, Sociodemographic Profile and Epidemiology of NonCommunicable Diseases in Oman. Oman Med J. 2012;27(5):425-443.

4. Lenfant C, Chobanian AV, Jones DW, Roccella EJ. Seventh report of the joint national committee on the prevention, detection, evaluation, and treatment of high blood pressure (JNC 7): Resetting the hypertensionsails. Hypertens. 2003;41:1178-1179.

5. Vasan RS, Larson MG, Leip E.P, Kannel WB, Levy D. Assessment of frequency of progression tohypertension in nonhypertensive participants in the Framingham heart study: A cohort study. Lancet. 2001;358:1682-1686.

6. Navarro-Gonzalez JF, Mora C, Muros M, Garcia J, Donate J, Cazana V. Relationship between inflammation and microalbuminuria in prehypertension. J Human Hypertens. 2013;27:119-125.

7. Celik T, Yuksel UC, Fici F, Celik M, Yaman H, Kilic S Vascular inflammation and aortic stiffness relate to early left ventricular diastolic dysfunction in prehypertension. Blood Press. 2013;22:94-100.

8. Player MS, King DE, Mainous AG, Geesey ME. Psychosocial factors and progression from prehypertension to hypertension or coronary heart disease. Ann Fam Med. 2007;5:403-411.

9. Suri M.F, Qureshi AI. Prehypertension as a risk factor for cardiovascular diseases. J Cardiovasc Nurs. 2006;21:478-482.

10. Yadav S, Boddula R, Genitta G. Prevalence and risk factors of pre-hypertension and hypertension in an affluent north Indian population. Indian J Med Res. 2008;128:712-720.

11. Pradeepa R, Mohan V. Hypertension and pre-hypertension in developing countries. Indian J Med Res. 2008;128:688-690.

12. Guo X, Zhang X, Hu J. The prevalence and heterogeneity of prehypertension: a meta-analysis and meta-regression of published literature worldwide. Cardiovasc J Afr. 2012;23:4450 .

13. Dong GH, Wang D, Liu MM, Liu YQ, Zhao Y, Yang M. Sex difference of the prevalence and risk factors associated with prehypertension among urban Chinese adults from 33 communities of China: The CHPSNE study. J. Hypertens. 2012;30:485-491 
14. Ganguly SS, Al-Shafaee MA, Bhargava K, Dutta Gupta KK. Prevalence of prehypertension and associated cardiovascular risk profiles among prediabetic Omani adults. BMC Public Health. 2008;8:108-115.

15. Ali Abdullah Al-Maqbali, Meredith Temple-Smith, John Ferler, Irene Blackberry. Prevalence and determinants of prehypertension among Omani adults attending noncommunicable disease screening program in primary care setting in Sohar city. Oman Med J. 2013;28(5):316-323.

16. World Health Organization. Anthropometric measurement techniques (Technical Report Series no. 894).Published 2000.http://www.who.int/nutrition/publications/obesity/WHO TRS_894/en/.

17. World Health Organization. Asia Pacific adaptations of WHO Body Mass Index classification. Published2006. http://apps.who.int/bmi/index.jsp?introPage=intro 3.html.

18. Sung R, Yu C, Choi K, McManus A. Waist circumference and body mass index in Chinese children: Cutoff values for predicting cardiovascular risk factors. Int J Obes. 2007;31:550558.

19. Browning LM, Hsieh S.D, Ashwell M. A systematic review of waist-to-height ratio as a screening tool for the prediction of cardiovascular disease and diabetes: 0.5 could be a suitable global boundary value. Nutr Res Rev. 2010;23:247-269.

20. Mohit Shahi, Chow Wen Li. Pre-hypertension and its correlation with cardiovascular risk factors: a study among health sciences students in Malaysia. J Integrat Health Sci. 2013;1(2):104-109.

21. Mona Soliman, Omaima El-Salamony, Khalid El Khashab, Naglaa A. El-Sherbiny, Safaa Khamis. Study of hypertension among Fayoum University students. Int J Public Health Res. 2014;2(2):15-9.

22. Silva DA, Petroski EL, Peres MA. Prehypertension and hypertension among adults in a metropolitanarea in southern Brazil: Population-based study. Rev. Saude Publica. 2012;46:988-998.

23. Rahmanian K, Shojaie M. The prevalence of pre-hypertension and its association to established cardiovascular risk factors in south of Iran. BMC Res. Notes.2012; 5.

24. Ferguson TS, Younger NO, Tulloch-Reid MK. Prevalence of prehypertension and its relationship to risk factors for cardiovascular disease in Jamaica: analysis from a crosssectional survey. BMC Cardiovasc Disord. 2008;8:20.

25. Mohan V, Deepa M, Farooq S, Datta M, Deepa R. Prevalence, awareness and control of hypertension in Chennai-The Chennai Urban Rural Epidemiology Study (CURES-52). $J$ Assoc Physicians India. 2007;55:326-332.

26. Portaluppi F, Pansini F, Manfredini R, Mollica G. Relative influence of menopausal status, age, and body mass index on blood pressure. Hypertens. 1997;29:976-979.
27. Staessen JA, Celis H, Fagard R. The epidemiology of the association between hypertension and menopause. J Human Hypertens. 1998;12:587-592.

28. Deepa R, Shanthirani CS, Pradeepa R, Mohan V. Is the "rule of halves" in hypertension still valid? Evidence from the Chennai Urban Population Study. J Assoc Physicians India. 2003;51:153-157.

29. Glasser SP, Basile JN, Lackland DT. Does prehypertension represent an increased risk for incident hypertension and adverse cardiovascular outcome? Hypertens. 2009;54:954-955.

30. Wang Y, Wang QJ. The prevalence of prehypertension and hypertension among US adults according to the new Joint National Committee guidelines: new challenges of the old problem. Arch Intern Med. 2004;164:2126-2134.

31. Zheng L, Sun Z, Zhang X. Predictors of progression from prehypertension to hypertension among rural Chinese adults: results from Liaoning Province. Eur J Cardiovasc Prev Rehabil. 2010;17:217-222.

32. Yu D, Huang J, Hu D. Prevalence and risk factors of prehypertension among Chinese adults. J Cardiovasc Pharmacol. 2008;52:363-368.

33. Tocci G, Ferrucci A, Passerini J. Prevalence of "borderline" values of cardiovascular risk factors in the clinical practice of general medicine in Italy: results of the BORDERLINE study. High Blood Press Cardiovasc Prev. 2011;18:43-51.

34. Erem C, Hacihasanoglu A, Kocak M, Deger O, Topbas M. Prevalence of prehypertension and hypertensionand associated risk factors among Turkish adults: Trabzon Hypertension Study. J Public Health (Oxf). 2009;31:47-58.

35. Ong KL, Cheung BM, Man YB, Lau CP, Lam KS. Prevalence, awareness, treatment, and control of hypertension among United States adults 1999-2004. Hypertens. 2007;49:69-75.

36. Li G, Wang H, Wang K, Wang W, Dong F, Qian Y. Prevalence, awareness, treatment, control and risk factors related to hypertension among urban adults in Inner Mongolia 2014: differences between Mongolian and Han populations. BMC Public Health. 2016;16:294.

37. Samuel I. Merino Barrera. Guillermo A, Pérez Fernández, Merlin Garí Llanes, Vielka González Ferrer, Beyda González Camacho, Francisco L. Moreno-Martínez. Factors associated with prehypertension in young adults between 20 and 25 years of age. Cor Salud. 2014;6(1):25-35.

How to cite this article: Anwar S, Aleem B, Moslhey G. J, Rashid H. H. Covariates of prehypertension in Oman. J Community Health Manag. 2018;5(4):192196. 